\title{
BMJ Open Pharmacist intervention for glycaemic control in the community (the RxING study)
}

\author{
Yazid N Al Hamarneh, ${ }^{1}$ Theresa Charrois, ${ }^{2}$ Richard Lewanczuk, ${ }^{3}$ Ross T Tsuyuki ${ }^{1}$
}

To cite: Al Hamarneh YN, Charrois T, Lewanczuk $\mathrm{R}$, et al. Pharmacist intervention for glycaemic control in the community

(the RxING study). BMJ Open 2013:3:e003154.

doi:10.1136/bmjopen-2013003154

- Prepublication history for this paper is available online. To view these files please visit the journal online (http://dx.doi.org/10.1136/ bmjopen-2013-003154).

Received 3 May 2013 Revised 12 August 2013 Accepted 13 August 2013

${ }^{1}$ Division of Cardiology, Department of Medicine, EPICORE Centre, University of Alberta, Edmonton, Alberta, Canada

${ }^{2}$ School of Pharmacy, Curtin University, Perth, Western Australia, Australia ${ }^{3}$ Department of Medicine, University of Alberta, Edmonton, Alberta, Canada

Correspondence to Ross T Tsuyuki; ross.tsuyuki@ualberta.ca

\section{ABSTRACT}

Objective: To determine the effect of a community pharmacist prescribing intervention on glycaemic control in patients with poorly controlled type 2 diabetes.

Design: Pragmatic, before-after design.

Setting: 12 community pharmacies in Alberta, Canada. Participants: Type 2 diabetes receiving oral hypoglycaemic medications and with glycated haemoglobin (HbA1c) of 7.5-11\%.

Intervention: Pharmacists systematically identified potential candidates by inviting patients with type 2 diabetes to test their $\mathrm{HbA1c}$ using validated point-of-care technology. Pharmacists prescribed 10 units of insulin glargine at bedtime, adjusted by increments of 1 unit daily to achieve a morning fasting glucose of $\leq 5.5 \mathrm{mmol} / \mathrm{L}$. The patients were followed up at 2, 4, 8, 14, 20 and 26 weeks. Primary outcome: Change in HbA1c from baseline to week 26.

Secondary outcomes: Proportion of patients achieving target $\mathrm{HbA1c}$, changes in oral hypoglycaemic agents, quality of life and patient satisfaction, persistence on insulin glargine, number of insulin dosage adjustments per patient and number of hypoglycaemic episodes.

Results: We screened 365 patients of whom 111 were eligible. Of those, $100(90 \%)$ were enrolled in the study; all 11 patients who did not consent refused to use insulin. Average age was 64 years (SD 10.4), while average diabetes duration was 10.2 years (SD 7). HbA1c was reduced from 9.1\% (SD 1) at baseline to 7.3\% (SD 0.9); a change of $1.8 \%$ (95\% Cl 1.4 to 2, $p<0.001)$. Fasting plasma glucose was reduced from 11 (SD 3.3) to $6.9 \mathrm{mmol} / \mathrm{L}$ (SD 1.8); a change of $4.1 \mathrm{mmol} / \mathrm{L}(95 \% \mathrm{Cl}$ of 3.3 to $5, p=0.007$ ). Fifty-one per cent of the patients achieved the target $\mathrm{HbA} 1 \mathrm{C}$ of $\leq 7 \%$ at the end of the study. Conclusions: This is the first completed study of independent prescribing by pharmacists. Our results showed similar improvements in glycaemic control as previous physician-led studies. RxING provides further evidence for the benefit of pharmacist care in diabetes.

Trial registration: clinicaltrials.gov; Identifier: NCT01335763.

\section{INTRODUCTION}

Currently, 347 million individuals are living with diabetes worldwide. ${ }^{1}$ Approximately $90 \%$

\section{ARTICLE SUMMARY}

Strengths and limitations of the study

- This is the first study of independent prescribing by pharmacists in patients with diabetes and it demonstrates a clinically important improvement in glycaemic control.

- The 26-week follow-up period can be considered relatively short; it is possible that with a longer study more patients may have achieved the target glycated haemoglobin (or fewer if patients discontinued their insulin).

- We did observe several 'hypoglycaemic-type symptoms', however we were not able to confirm these as true hypoglycaemia. We also have no frame of reference as patients may have experienced some of these symptoms prior to enrolling in our study. Finally, the number of reported 'hypoglycaemic-type symptoms' in this study was consistent with the findings reported in the literature.

of them have type 2 diabetes. ${ }^{1}$ The number of new cases of type 2 diabetes is rapidly increasing mainly because of obesity and an ageing population. $^{2}$

Because of its chronic nature and the severe complications associated with it, diabetes carries a health and a financial burden on the affected individual and health systems. ${ }^{3}$ Poorly controlled diabetes puts patients at high risk of suffering from macrovascular and microvascular complications. ${ }^{4}$

Type 2 diabetes is a progressive disease; it has been reported that $50 \%$ of the insulinproducing capacity is lost at the time of diagnosis with an average loss rate of $5 \%$ per year afterwards. ${ }^{5}$ As a result, many patients with type 2 diabetes will eventually require the use of insulin; however, clinicians seem reluctant to start insulin ${ }^{6}$ despite evidence from studies such as INSIGHT, which demonstrated improved glycaemic control with the addition of insulin glargine to oral hypoglycaemic agents in patients with type 2 diabetes $^{7}$ as well as guidelines that recommend 
starting insulin immediately if the patient's glycated haemoglobin (HbAlc) is $\geq 9 \%{ }^{8}$

Clinicians' reluctance to initiate insulin due to unfamiliarity with the treatment or using it as a last resort ${ }^{9}$ plays a major role in influencing the patient's decision to start insulin treatment regimen. It has been reported that many patients have 'psychological insulin resistance' where they are unwilling to take insulin because of certain beliefs that insulin will not be beneficial and in some cases it may even be harmful. Personal experience and messages from different healthcare professionals can also affect the patient's decisions regarding insulin treatment regimen. ${ }^{6} 10$

Pharmacists are front line healthcare professionals who see patients with diabetes more frequently than physicians (15 vs 7 times/year) ${ }^{11}$ and as such, could proactively and systematically identify patients with poorly controlled type 2 diabetes in a broad-based public health approach to chronic disease management. ${ }^{12}$ Indeed, there is good evidence for the efficacy of pharmacist care in diabetes. ${ }^{13} \mathrm{In}$ community settings, pharmacists have demonstrated that they are capable of identifying poorly controlled patients, educate patients regarding diabetes, medications and selfmonitoring of plasma glucose, provide adherence support, identify and resolve diabetes problems and complications and setting goals to reduce the patients' $\mathrm{HbAlc}$, plasma glucose and improve their quality of life and other comorbidities. ${ }^{42-16}$ Moreover, the scope of practice for pharmacists in Alberta is changing, allowing pharmacists to prescribe medications and order laboratory tests. As such, there is an unprecedented opportunity to identify and improve glycaemic control in patients with type 2 diabetes.

The main aim of the RxING study was to determine the effect of a community pharmacist prescribing intervention on glycaemic control in patients with poorly controlled type 2 diabetes.

\section{METHODS}

\section{Study design and setting}

RxING was a multicentre pragmatic before-after design trial, which was conducted in 12 community pharmacies in the province of Alberta, Canada.

We chose the before-after design because we had concerns about withholding insulin from this high-risk group. The concerns were based on guidelines recommendations $^{8}$ and the evidence from studies such as INSIGHT. ${ }^{7}$

All participating pharmacists, who were either certified diabetes educators (CDE) or preparing to be $\mathrm{CDE}$, received face-to-face training by the study team. The training material was based on the most recent Canadian guidelines and recommendations. ${ }^{78}$ They also received a manual of operations to help them conduct the study.

\section{Study participants}

We recruited adults who had physician diagnosed type 2 diabetes for at least 6 months and were receiving one or more oral hypoglycaemic agents, had an HbAlc between $7.5 \%$ and $11 \%$ and who were willing to sign an informed consent.

We excluded patients who were unwilling to use insulin, previously or currently using insulin (confirmed by the patient's medication records), had a history of ketoacidosis (confirmed by the patient's healthcare records), were pregnant, worked night shifts, had renal impairment (serum creatine of $\geq 124 \mathrm{mmol} / \mathrm{L}$ for females or $\geq 133 \mathrm{mmol} / \mathrm{L}$ for males; confirmed by the patient's healthcare records), were clinically unstable (based on the pharmacist's judgement), were unwilling or unable to attend follow-up visits or felt to be unlikely to adhere to study procedures due to cognitive limitations (based on the pharmacist's judgement), severe psychiatric disorders or alcoholism (confirmed by the patient's healthcare records).

\section{Recruitment}

Pharmacists systematically identified potential candidates from within their practice by inviting patients with type 2 diabetes (eg, patients on metformin) to test their HbAlc in the pharmacy using validated point of care technology (DCA Vantage, Siemens, Tarrytown, New York, USA). If the result of the HbAlc test was high $(7.5-11 \%)$ and the patient met the other inclusion criteria for the study the patient was asked if he/she wanted to participate in the study. After providing written informed consent, the patient was enrolled in the study. If HbAlc was $>11 \%$ the patient was assessed by the study investigators and the patient was referred to his/her physician.

\section{Intervention}

The patient was prescribed 10 units insulin glargine at bedtime and was asked to titrate the dose by 1 unit/day to achieve a fasting plasma glucose (FPG) of $\leq 5.5 \mathrm{mmol} / \mathrm{L}$. 717 The intervention also included patient education regarding insulin use, dose titration and self-monitoring. Patients contacted the pharmacist when they reached a FPG of $6 \mathrm{mmol} / \mathrm{L}$. All patients remained on their previously prescribed oral hypoglycaemic agent(s). If the combination with insulin was not approved in Canada, the oral hypoglycaemic agent was discontinued (eg, thiazolidinedione). Adjustments were made at the discretion of the treating pharmacist based on the most recent Canadian guidelines. The patient's family physician received a letter from the pharmacist to inform him/her that the patient was participating in the study.

\section{Follow-up}

Patients were followed at 2, 4, 8, 14, 20 and 26 weeks to provide ongoing care, check adherence to the insulin regimen, fasting blood sugars (measured by the patient), insulin dose and titration and adverse events. HbAlc was measured at weeks 14 and 26 using the same technique used at baseline. Family physicians were kept 
informed of patient's progress and any medication change after each visit.

\section{Outcomes}

The primary outcome measure was the change in HbAlc from baseline to week 26. Secondary outcomes included proportion of patients achieving target HbAlc (defined as HbAlc $\leq 7.0 \%$ ), changes in oral hypoglycaemic agents, quality of life and patient satisfaction using Audit of Diabetes-Dependent Quality of Life (ADDQoL), Diabetes Treatment Satisfaction Questionnaire (DTSQ) and Diabetes Treatment Satisfaction (Change) Questionnaire (DTSQc), persistence on insulin glargine (\% still taking insulin at the end of follow-up), number of insulin dosage adjustments per patient, number of hypoglycaemic episodes.

\section{Sample size calculation}

With a sample size of 80 patients and the following assumptions, an SD of 1.1 and a two-sided $\alpha$ of $0.05,{ }^{7}$ we

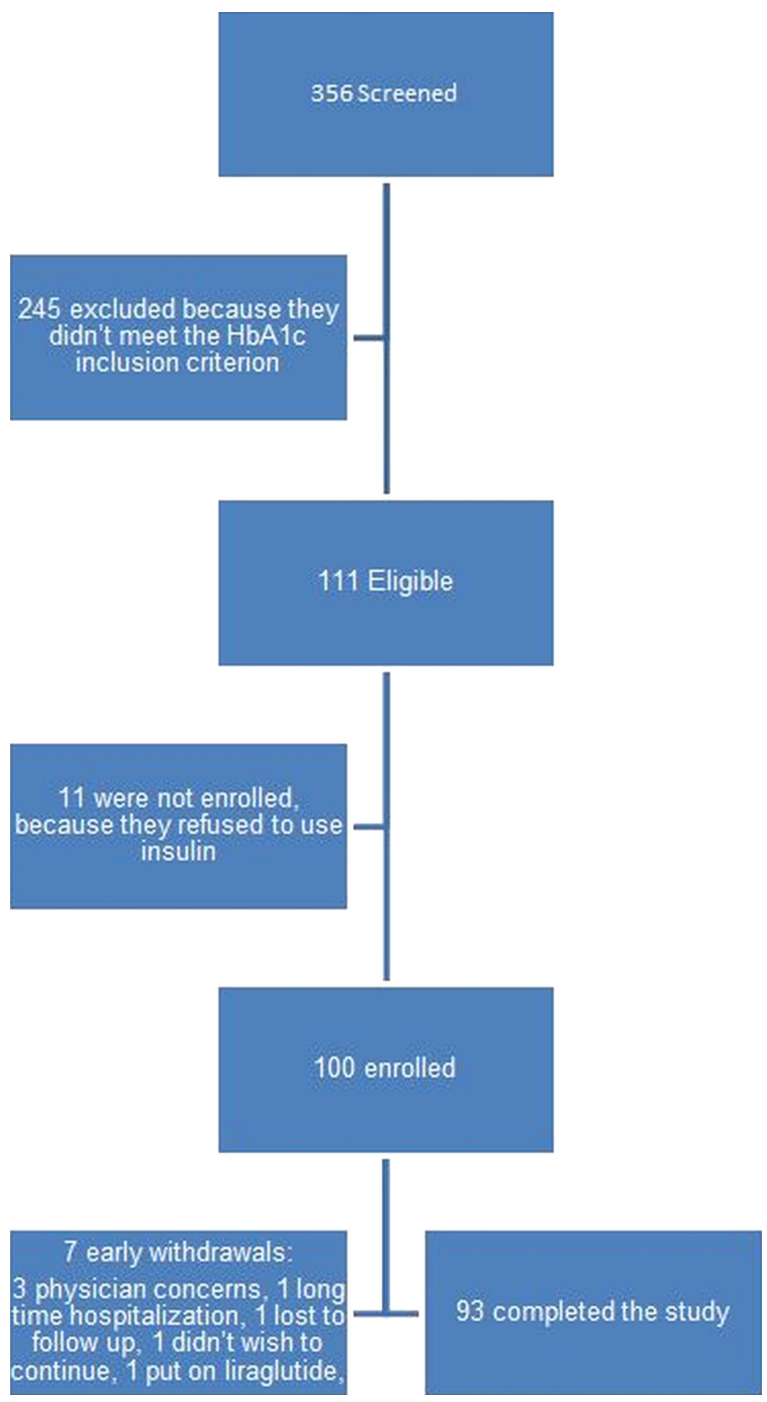

Figure 1 Patients' screening and enrolment flow chart. calculated $90 \%$ power to detect a mean decrease in HbAlc of $0.4 \%$. Since this a pragmatic, practice-based trial, the sample size was inflated to 100 to account for possible losses to follow-up.

\section{Data analysis}

The level of significance was set at 0.05. All analyses were performed on intention to treat basis. Missing data

Table 1 Demographic and clinical characteristics of the patients $(\mathrm{N}=100)$

\begin{tabular}{|c|c|}
\hline Characteristic & Frequency \\
\hline \multicolumn{2}{|l|}{ Gender } \\
\hline Male & 58 \\
\hline Female & 42 \\
\hline \multicolumn{2}{|l|}{ Marital status } \\
\hline Single & 8 \\
\hline Married & 77 \\
\hline Divorced & 9 \\
\hline Widowed & 6 \\
\hline \multicolumn{2}{|l|}{ Education } \\
\hline Grade school & 10 \\
\hline High school & 36 \\
\hline Some postsecondary education & 26 \\
\hline Postsecondary education & 28 \\
\hline \multicolumn{2}{|l|}{ Employment } \\
\hline Caring for family & 1 \\
\hline Working for profit/pay & 36 \\
\hline Unemployed/looking for a job & 6 \\
\hline Retired & 48 \\
\hline Other & 9 \\
\hline \multicolumn{2}{|l|}{ Self-reported ethnicity } \\
\hline Aboriginal/first nation & 1 \\
\hline White & 89 \\
\hline South Asian & 1 \\
\hline Oriental & 4 \\
\hline Other & 4 \\
\hline Declined & 1 \\
\hline \multicolumn{2}{|l|}{ Medication coverage } \\
\hline Private & 29 \\
\hline Government & 47 \\
\hline Out of pocket & 15 \\
\hline Private and government & 7 \\
\hline Private and out of pocket & 2 \\
\hline \multicolumn{2}{|l|}{ Smoking status } \\
\hline Smoker & 22 \\
\hline Ex-smoker & 41 \\
\hline Non-smoker & 37 \\
\hline \multicolumn{2}{|l|}{ Alcohol consumption } \\
\hline No alcohol & 43 \\
\hline Occasional alcohol (eg, 1-3 drinks/week) & 54 \\
\hline $1-2$ alcohol drinks/day & 3 \\
\hline \multicolumn{2}{|l|}{ Self-reported hypertension } \\
\hline Yes & 63 \\
\hline No & 36 \\
\hline Unknown & 1 \\
\hline \multicolumn{2}{|l|}{ Self-reported high cholesterol } \\
\hline Yes & 64 \\
\hline No & 33 \\
\hline Unknown & 3 \\
\hline
\end{tabular}


were imputed using a last value carried forward strategy. The mean HbAlc between baseline and 26 weeks was compared using paired t test. Secondary outcomes were analysed using paired $\mathrm{t}$ tests and basic frequencies. Linear regression was used to adjust for the patients' demographics and clinical characteristics.

\section{RESULTS}

We screened 356 patients with type 2 diabetes; 245 were excluded because they did not meet the HbAlc inclusion criteria. Of the 111 eligible patients, 11 were not enrolled because they refused to use insulin, leaving 100 patients enrolled (figure 1).

The demographic and clinical characteristics of the patients are reported in table 1 . Patients' mean age was 64 years (SD 10.4) and had a diabetes duration of 10.2 years (SD 7). Fifty-eight per cent of the patients were men, $77 \%$ were married and $90 \%$ reported having at least high school education. Nearly half of the patients $(48 \%)$ were retired, almost ninety per cent $(89 \%)$ were white (ethnicity was self-reported) and nearly half (47\%) have a government medication coverage. Around onequarter of the patients $(22 \%)$ reported that they were smokers and more than half $(54 \%)$ reported occasional consumption of alcohol (eg, 1-3 drinks/week). Nearly two-thirds of the patients had elevated blood pressure (63\%) and elevated cholesterol (64\%; hypertension and high cholesterol were self-reported).

All but one patient was taking insulin glargine at the end of the study (he stopped his insulin before the final visit because his plasma glucose readings were 'good'). At the end of the study the mean insulin glargine dose was 31.1 units (SD 18.4) with a mean of 21.1 dose adjustments (SD 18.8) per patient.

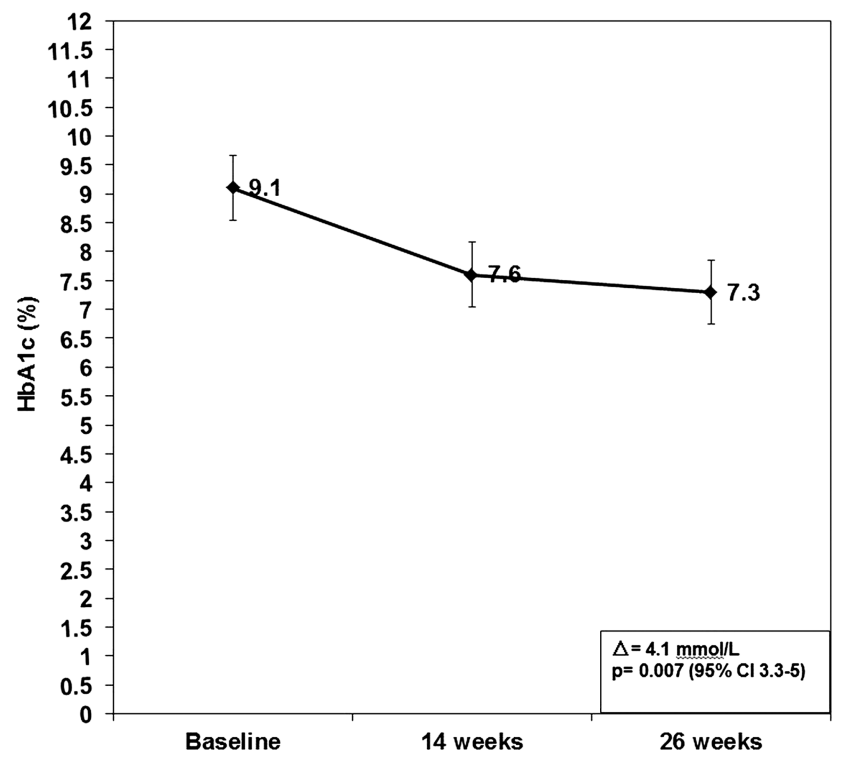

Figure 2 Intervention effect on glycated haemoglobin in patients with uncontrolled type 2 diabetes $(n=100)$.

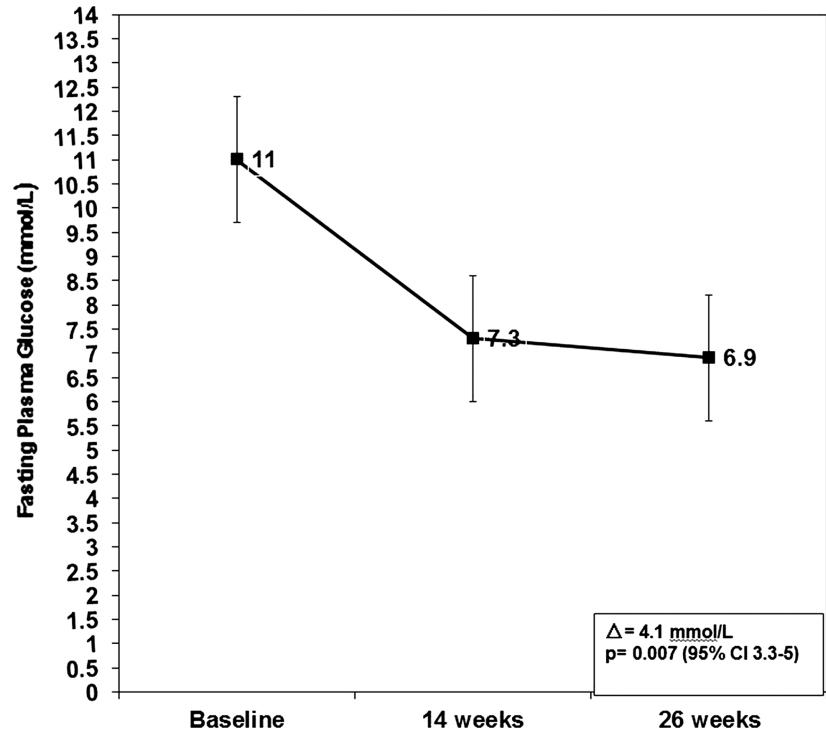

Figure 3 Intervention effect on fasting plasma glucose in patients with uncontrolled type 2 diabetes $(n=100)$.

HbAlc was reduced from $9.1 \%$ (SD 1) at baseline to $7.3 \%$ (SD 0.9$)$ at 26 weeks, a change of $1.8 \%(95 \%$ CI 1.4 to 2, $\mathrm{p}<0.001$; figure 2), whereas FPG was reduced from $11 \mathrm{mmol} / \mathrm{L}$ (SD 3.3) at baseline to $6.9 \mathrm{mmol} / \mathrm{L}$ (SD 1.8) at 26 weeks, a change of $4.1 \mathrm{mmol} / \mathrm{L}(95 \%$ CI of 3.3 to 5 , $\mathrm{p}=0.007$; figure 3 ).

Fifty-one per cent of the patients achieved the target HbAlc of $\leq 7 \%$ at the end of the study. At baseline, two-thirds $(66 \%)$ of the patients were taking two or more medications (table 2), the most widely used combination was metformin and gliclazide, followed by metformin and glyburide and metformin and repaglinide. Nearly half of the patients (48\%) had their oral hypoglycaemic regimen altered (table 3); the most frequent alterations were stopping sulfonylurea $(46 \%)$ followed by initiating meglitinides (23\%), stopping metformin (21\%) and stopping thiazolidinedoine and dipeptidyl peptidase 4 inhibitors (19\%). Those alterations were made by the pharmacists who then informed the patients' family physicians.

Only $40 \%$ of the patients returned quality-of-life and treatment satisfaction questionnaires. Of those, only 30 questionnaires were analysable. Quality of life and treatment satisfaction have improved by 0.2 and 3.5 , respectively among the patients who returned the questionnaires.

Table 2 Number of oral hypoglycaemic agents used by patients and mean glycated haemoglobin (HbA1c)

\begin{tabular}{lll}
\hline Number of oral agents & Frequency & Mean HbA1c (SD) \\
\hline 1 & 34 & $8.7(0.9)$ \\
2 & 56 & $9.1(0.9)$ \\
3 & 7 & $9.8(1.6)$ \\
4 & 3 & $8.7(0.7)$ \\
\hline
\end{tabular}


Table 3 Oral hypoglycaemic use at baseline and the end of the study

\begin{tabular}{lll}
\hline Medication & $\begin{array}{l}\text { Baseline } \\
(\mathbf{N}=100)\end{array}$ & $\begin{array}{l}\text { 26 Weeks } \\
\mathbf{( N = 9 3 )}\end{array}$ \\
\hline Metformin & 88 & 78 \\
Sulfonylurea & 54 & 32 \\
Meglitinides & 18 & 29 \\
Dipeptidyl peptidase 4 & 12 & 3 \\
Thiazolidinedione & 9 & 0 \\
\hline
\end{tabular}

Body mass index was 31.6 (SD 6.3) at baseline and 32.6 (SD 6.3) at the end of follow-up $(\mathrm{p}=0.29)$ and waist circumference was $106 \mathrm{~cm}$ (SD 13.8) at baseline and $107.4 \mathrm{~cm}$ (SD 12.9) at the end of follow-up ( $\mathrm{p}=0.5)$.

'Hypoglycaemic-type' symptoms were reported by 54 patients. Only two of these episodes required medical attention (one caused a visit to the family physician while the other required a visit to the emergency department without an overnight stay). We were neither able to confirm whether these episodes were true hypoglycaemia, through blood glucose measurements, nor did we have baseline information on such symptoms.

\section{DISCUSSION}

We found that a community pharmacist prescribing intervention in patients with poorly controlled type 2 diabetes improved patients' $\mathrm{HbAlc}$ by an absolute value of $1.8 \%(95 \%$ CI 1.4 to $2, \mathrm{p}<0.001)$ and FPG by $4.1 \mathrm{mmol} / \mathrm{L}(95 \%$ CI of 3.3 to $5, \mathrm{p}=0.007)$. This is the first study of independent prescribing by pharmacists in patients with diabetes and represents a clinically important improvement in glycaemic control.

Our findings are consistent with the findings of Gerstein $e t a l^{7}$ and Harris $e t a l^{9}$ who compared the effect of adding insulin glargine to the oral hypoglycaemic regimen versus the conventional therapy where oral hypoglycaemic agent doses were adjusted. They reported better glycaemic control in the insulin glargine group after 26 weeks of follow-up. Our findings are also consistent with the findings of Wubben and Vivian ${ }^{13}$ who conducted a systematic review to assess the effectiveness of pharmacist intervention in patients with diabetes in outpatient settings. They reported additional $\mathrm{HbA1c}$ reduction (when compared to usual care) of $0.5 \%$ when pharmacists did not have prescribing authority and 1\% when pharmacists had prescribing authority (collaborative prescribing in this case).

It has been reported in the literature that the adherence rates to the insulin regimen are unsatisfactory ${ }^{18}$; however in our study, $99 \%$ of the patients were adherent to their treatment regimen for 6 months. This can be explained by the intensive intervention provided by the pharmacist and the relatively short duration of the study.

This study is not without limitations. The 26-week follow-up period can be considered relatively short; it is possible that with a longer study more patients may have achieved the target HbAlc (or fewer if patients discontinued their insulin). Patients who were unwilling to use insulin were excluded from the study; however, patients' willingness to use insulin was high in our pilot study ${ }^{4}$ and also during the screening process. The proactive and systematic approach that we used in this study also helped in identifying patients who could benefit from insulin. We acknowledge that adding insulin to the oral hypoglycaemic agent(s) regimen is one of the options that are available to improve glycaemic control; however, this choice was based on the insulin's efficacy and safety profile. The response rate to quality-of-life and treatment satisfaction questionnaires was low; however, the improvements in quality of life and treatment satisfactions are consistent with the findings of Gerstein $e t a l^{7}$ who reported improvements in treatment satisfaction in the insulin glargine group. We also received unsolicited comments from different patients highlighting their pleasure and satisfaction with treatment and its impact on their daily activities.

We did observe several 'hypoglycaemic-like' symptoms; however, we were not able to confirm these as true hypoglycaemia. We also have no frame of reference as patients may have experienced some of these symptoms prior to enrolling in our study. Finally, the number of reported 'hypoglycaemic-type symptoms' in this study was consistent with the findings of a meta-analysis of more than 1100 diabetes patients who were using insulin glargine. $^{19}$

Our findings take the evidence for the benefits of pharmacist care in diabetes one step further. That prescribing insulin improves glycaemic control in itself is perhaps not surprising; what is important is that pharmacists can systematically identify patients with poor glycaemic control, educate and support patients to achieve better outcomes. Since pharmacists see patients with diabetes frequently, ${ }^{11}$ this can be an attractive approach.

Acknowledgements The authors would like to acknowledge the participation of the following pharmacists and pharmacies in making this study possible: Rick Siemens (London Drugs, Lethbridge), Darsey Milford (Turtle Mountain Pharmacy, Bellevue), Rita Bowron, Rami Chowaniec, Nader Hammoud, Carol Wei, Sheilah Kostecki (Safeway Pharmacy, Edmonton and Calgary), Anita Brown (Shoppers Drug Mart, Okotoks), Janelle Fox, Tony Nickonchuck (Walmart Pharmacy Cold Lake and Peace River), Rita Lyster (Rita's Apothecary and Home Healthcare, Barrhead) and Anita and Warren Dobson (Medicine Shoppe, Calgary).

Contributors All the authors have made substantial contributions to the article. YNAH had full access to all of the data in the study and takes responsibility for the integrity of the data and the accuracy of the data analysis. RTT and TC were involved in study concept and design. RTT and YNAH were involved in acquisition, analysis, interpretation of the data, statistical analysis and drafting of the article. RTT, RL, TC and YNAH contributed in critical revision of the article for important intellectual content and provided administrative, technical and material support. RTT and RL were involved in study supervision.

Funding This work was supported by unrestricted investigator-initiated funding provided by Sanofi Canada and the testing equipments were provided by ManthaMed. 
Competing interests None.

Patient consent Obtained.

Ethics approval Health Research Ethics Board of the University of Alberta.

Provenance and peer review Not commissioned; externally peer reviewed.

Data sharing statement No additional data are available.

Open Access This is an Open Access article distributed in accordance with the Creative Commons Attribution Non Commercial (CC BY-NC 3.0) license, which permits others to distribute, remix, adapt, build upon this work noncommercially, and license their derivative works on different terms, provided the original work is properly cited and the use is non-commercial. See: http:// creativecommons.org/licenses/by-nc/3.0/

\section{REFERENCES}

1. World Health Organization. Diabetes. 2012. http://www.who.int/ mediacentre/factsheets/fs312/en/ (accessed Feb 2013).

2. Lipscombe LL, Hux JE. Trends in diabetes prevalence, incidence and mortality in Ontario, Canada 1995-2005: a population based study. Lancet 2007;369:750-6.

3. World Health Organization. Diabetes: the cost of diabetes. 2012. http:// www.who.int/mediacentre/factsheets/fs236/en/ (accessed Feb 2013).

4. Al Hamarneh YN, Rosenthal M, Tsuyuki RT. Glycemic control in community-dwelling patients with type 2 diabetes. Can Pharm $\mathrm{J}$ 2012;2:68-9 e1.

5. Lebovitz HE. Insulin secretagogues: old and new. Diabetes Rev 1999;7:139-53.

6. Polonsky $\mathrm{WH}$, Jackson RA. What's so tough about taking insulin? Clin Diabetes 2004;22:147-50.

7. Gerstein HC, Yale JF, Harris SB, et al. A randomized trial of adding insulin glargine vs. avoidance of insulin in people with type 2 diabetes on either no oral glucose-lowering agents or submaximal doses of metformin and/or sulphonylureas. The Canadian INSIGHT study. Diabet Med 2006;23:736-42.
8. Canadian Diabetes Association. Canadian Diabetes Association 2008 clinical practice guidelines for the prevention and management of diabetes in Canada. Can J Diabetes 2008;32:s1-201.

9. Harris S, Yale JF, Dempsey E, et al. Can family physicians help patients initiate basal insulin therapy successfully? Randomized trial of patient-titrated insulin glargine compared with standard oral therapy: Lessons for family practice from Canadian INSIGHT trial. Can Fam Physician 2008;54:550-8.

10. Polonsky WH, Fisher L, Guzman S, et al. Psychological insulin resistance in patients with type 2 diabetes. Diabetes Care 2005;28:2543-5.

11. Shiu JR, Simpson SH, Johnson JA, et al. Quantifying opportunities to affect diabetes management in the community. Can Pharm $J$ 2006;139:37-8.

12. O'Donovan D, Byrne S, Sahm L. The role of pharmacists in control and management of type 2 diabetes mellitus; a review of the literature. J Diabetol 2011;1:5-21.

13. Wubben DP, Vivian EM. Effects of pharmacist outpatient interventions on adults with diabetes mellitus: a systematic review. Pharmacotherapy 2008;28:421-36.

14. Armour CL, Taylor SJ, Houriham F, et al. Implementation and evaluation of Australian pharmacists' diabetes care services. J Am Pharm Assoc 2004:44:455-66.

15. Fornos JA, Andres NF, Andres JC, et al. A pharmacotherapy follow-up program in patients with type-2 diabetes in community pharmacies in Spain. Pharm World Sci 2006;28:65-72.

16. Krass I, Armour CL, Mitchell B, et al. The pharmacy diabetes care program: assessment of a community pharmacy diabetes service model in Australia. Diabet Med 2007;24:677-83.

17. Strange P. Treat-to-target insulin titration algorithms when initiating long or intermediate acting insulin in type 2 diabetes. J Diabetes Sci Technol 2007;1:540-8.

18. Hartman I. Insulin analogs: impact on treatment success, satisfaction, quality of life and adherence. Clin Med Res 2008;6:54-67.

19. Rosenstock J, Dailey G, Massi-Benedetti M, et al. Reduced hypoglycemia risk with insulin glargine in type 2 diabetes. Diabetes Care 2005;28:950-5. 


\section{Correction}

Al Hamarneh YN, Charrois T, Lewanczuk R, et al. Pharmacist intervention for glycaemic control in the community (the RxING study). BMJ Open 2013;3:e003154. Figure 2 of this article was published with incorrect text in the change box. The correct text is: $\Delta=1.8 \%$; $\mathrm{p}<0.001$ (95\% CI 1.4-2). We apologise for this error.

BMJ Open 2013;3:e003154corr1. doi:10.1136/bmjopen-2013-003154corr1 